ISSN: 2379-2922

\title{
Nursing Informatics Competency Based Assessment for Nursing Personnel in Primary Healthcare Centers in Tabuk
}

\author{
Zakiah Eid Al-Balawi ${ }^{1}$, Eman Salman Taie ${ }^{2}$, Naglaa Alsesei ${ }^{3}$ \\ ${ }^{1}$ Faculty of Nursing, King Abdul Aziz University, KSA. \\ ${ }^{2}$ Professor of Nursing Administration, Faculty of Nursing, Helwan University, Egypt. \\ ${ }^{3}$ Assist Prof of Nursing, Administration Alexandia University, Egypt. \\ Dr_emys@hotamil.com
}

\begin{abstract}
Background: Nursing informatics is the specialty that integrates nursing science, information science, computer science, and cognitive science for the purpose of identify, manage, communicate and enhance healthcare data, information, knowledge, and wisdom to improve patient care and the nursing profession

Aim: To assess nursing informatics competencies for nursing personnel in primary healthcare centers in Tabuk.

Method: It is descriptive study. The study was conducted primary healthcare centers in Tabuk. Distributed based on proximity from the Hospitals into (king Khaled Hospital sector and King Fahad Hospital sector). Study subjects composed (217) nurses personnel. Nursing Informatics Competencies Questionnaire used for data collection.

Results: The highest percentage of nursing personnel was female. More than half of study sample had associated nursing degree and less than one third of them had bachelor degree in nursing. About half of study subjects were capable of computer literacy competency and Informatics Literacy Competency. Meanwhile, about one third of them were capable in Information Management Literacy Competency. More than half of them were capable regarding total nursing informatics competencies.
\end{abstract}

Conclusion: More than half of them were capable regarding total nursing informatics competencies. Meanwhile, more than one third were partially capable and less than one quarter of them was not capable.

Recommendation: Involve nursing informatics competencies in nursing personnel performance appraisal. Conducts competency based nursing informatics training programs for nursing personnel according to their needs and to be up to date with new competencies. Develop curricular based competencies and further researches to investigate correlation between nursing informatics competencies and patient safety.

Keywords: Nursing Informatics, Informatics Competencies, Computer literacy, Information literacy, Informatics Literacy.

\section{INTRODUCTION}

Nursing informatics is the specialty that integrates nursing science, information science, computer science, and cognitive science for the purpose of identify, manage, communicate and enhance healthcare data, information, knowledge, and wisdom to improve patient care and the nursing profession (McGonigle, Hunter et al. 2014, ANA 2015). Supporting "Triple Aim" of healthcare, which is improving care provided, enhancing population health, and minimizing cost of healthcare services is a major goal of nursing informatics (Houston, Dieckhaus 
Nursing Informatics Competency Based Assessment for Nursing Personnel in Primary Healthcare Centers in Tabuk

et al. 2018)."This support is accomplished through the use of information structures, information processes, and information technology "(ANA 2015).

Although the nursing informatics is relatively new specialty in nursing field, but it has been proven that it contributed in the nursing practice, research, education and administration. Nursing informatics is serve as a tool to provide high quality and safety patient care, enabling the organization to translate data into meaningful knowledge which in turn helping in increase efficiently and effectively of healthcare services and thus reflected in the overall organization outcome (Elsayed, Hussein et al. 2017).

Competence referred to the required integration of knowledge, skills and abilities which includes the concept of value, attitudes, critical thinking, and clinical decision making that nurses should possess to fulfill specific task (Greer 2012, Chung and Staggers 2014, ANA 2015) Chung and Staggers 2014. Having competency in nursing leads to providing safe and high quality nursing practice, ensuring appropriate intervention, helps develop nursing as a profession, improve nursing education and recognition of one's limitations (Karami, Farokhzadian et al. 2017). Nursing informatics competencies (NIC) definition is an" acceptable level of knowledge, skill, and ability to complete specific informatics tasks" (Hunter, McGonigle et al. 2013).

Nowadays, technology is integral part in every role of nurses, \{Sheikh, 2015 \#4\} nursing informatics competencies crucial competencies required in the contemporary healthcare system. When nurses have an expected level of informatics practice, they will utilizing patient data in way that grantees increase quality maximize outcome, enhance patient satisfaction and promoting evidence-based practice (Liston and McKinnon 2017)

\section{SigNIFICANT OF THE STUDY}

Ministry of health (M.O.H) in Saudi Arabia have 2020-2030 strategic goals state that" to improve the efficiency and effectiveness of the healthcare sector through the use of information technology and digital transformation" (Bassi 2016).

Nurses compromise the majority of the workforce in any healthcare setting, and they are the front line who using healthcare technologies and communicate with patient thus, they play an significant role in the adoption and evaluation of any health information system (Zadvinskis, Smith et al. 2018). As information technologies in healthcare continues to evolve and change, ensuring nurses poses the expected level of nursing informatics competencies is imperative in today technological working environment (Jing, Zhang et al. 2019).

However, nurses with different roles and settings contribute in some way to create new knowledge and participate in changing clinical or administrative decisions. They are helping translating clinical data into meaningful knowledge that leading to changing the nursing practice and decisions. Despite not all nurses is informatics nursing specialists but it is necessary for all nurses to understand the nursing informatics (Houston, Dieckhaus et al. 2018).

Moreover, existing literature has been demonstrated that adopting modern health information technologies by healthcare institutions does not leading to desired benefits until verifying from effective and efficient utilization of these technologies (Strudwick, McGillis Hall et al. 2018)

Finally, locally with dramatically and technological involvement in healthcare sectors but there is scarcity of published research regrading nursing informatics competencies (Alshammari, Pasay-an et al. 2017). Furthermore, the published researches indicate more research needed with diverse sample because the majority of the sample participants is limited to participants who have a bachelor's degree in nursing and ignore the other with below than bachelor degree who often do not have a minimum background in computer 
or information literacies (Forman, Armor et al. 2020).This emphasize the emerge for instigating the nursing informatics competencies level among nursing personnel which will in turn provide the baseline to help designing formal and continuous professional education base competencies thus will improve nursing informatics competencies.

\section{RESEARCH AIM}

- The aim of this study is to assess nursing informatics competencies for nursing personnel in primary healthcare centers in Tabuk through:

- Determine computer literacy competencies for nursing personnel in selected setting.

- Identify informatics literacy competencies for nursing personnel in selected setting.

- Identify information management competencies for nursing personnel in selected setting.

\section{RESEARCH QUESTION}

What are the nursing informatics competencies for nursing personnel in primary healthcare centers in Tabuk?

\section{SubJeCtS ANd Methods}

\section{Research Design}

Descriptive design used in this study.

\section{Study Setting}

The study was conducted in Primary Healthcare Centers (PHCs) in Tabuk. Thirty four primary healthcare centers at Tabuk city which distributed based on proximity from the Hospitals into (king Khaled Hospital sector and King Fahad Hospital sector).

\section{Subject}

Simple random sampling technique which used in this study to recruit sample out of 498 nurses personnel who are working in PHCs at Tabuk. 217 nursing personnel with experience at least six months in this working place were included (six month and above to be sure that the nurse has access or user name in workplace system). On the other hand, nursing personnel who have training in nursing informatics competency were excluded from study subjects.

\section{Tool of Data Collection}

\section{Nursing Informatics Competencies Questionnaire}

\section{It consists of two Parts}

Part I: Personal data nursing personnel. It includes (age, gender, level of education in nursing, years of experience as nurse, area of assignment and if attend any of nursing informatics training course before).

Part II: Nursing Informatics Competencies Questions. It included 49 Items.It consists of three dimensions (computer literacies, information management literacies and informatics literacies) the researcher used those three dimensions guided by Technology Informatics Guiding Educational Reform (TIGER) model of nursing informatics competencies (Hunter et al., 2013). First dimension was computer literacies (14 questions). Second dimension was information management literacies (15 questions). Third dimension was informatics literacies (20 questions). 


\section{SCORING SYSTEM}

Subject response was on three points of Likert scale ranging from 0-2: (0) referred to not capable to do, (1) referred to partially capable to do and (2) referred to capable to do. The scoring system of Nursing Informatics Competencies Questionnaire ranged (49-98).

- $\quad$ Scores less than (49 or $>50 \%$ ) was not capable.

- Scores less than $(74$ or $>75 \%)$ was partially capable.

- Scores equal and more than $(75$ or $<75 \%)$ was capable.

The Cronbach Alpha coefficient of the instrument was 0.948 for the study sample. The instrument had high construct validity. It was self-administered questionnaire.

\section{Pilot STUdy}

It was conducted at the beginning of the study and carried out on $10 \%(\mathrm{~N}=21)$ of the total sample size, to test applicability and clarity of the tool and time needed to fulfill the questionnaire. The time needed to fulfill the questionnaire was (15-20) minutes. The questionnaire was clear for study subjects and no modifications were required. So, the pilot study sample was included in the study sample.

\section{FIELD WORK}

The field work of this study was executed in two months. After the permission obtained from administration of king Fahad and king Khaled sectors then from the selected PHCs administration, the researcher began questionnaires distribution. Then, the researcher handed questionnaires personally to every participant and explained to them that, they have the right to withdraw from the study at any time and all filled questionnaires will be coded for analyzing purpose then they will be discarded. However, each copy contained informed consent. Then each one of study participant read and signed and filled the questioners voluntarily. Data collection began on beginning of February 2020 and was completed by the end of March 2020. The researcher started to use the developed tools with selected sample participants in their settings according to the available time for each of them after explaining to them the purpose of the study. A total of 217 nursing personnel completed the survey from selected PHCs with $100 \%$ response rate as all distributed questionnaires. The required time by each participant for filling the tool was ranged (15-20) minutes.

\section{AdMinistrative AND ETHical Considerations}

After obtaining the ethical approval for data collection from ethical committee at King Abdulaziz University. To carry out the study in the predetermined PHCs, an Official letter sent from postgraduate studies, Nursing College, King Abdul-Aziz University to Health Affairs Directorate in Tabuk. Then the researcher obtained the ethical approval from research department in Health Affairs Directorate in Tabuk. The researcher obtained study subject approval through informed consent attached to each questionnaire after explaining purpose and method of data collection of the study. Ethics, values, culture and belief was respected. Confidentiality, anonymity and right to withdraw from study any time were granted.

\section{STATistical Analysis}

Data were analysed using Statistical Package for Social Science (SPSS) version 21.0. Chicago, Illinois, USA. Quantitative data were expressed as mean \pm standard deviation. Qualitative data were expressed as count and proportion. $\mathrm{P}<0.05$ was considered significant and $\mathrm{P}<0.01$ was considered highly significant. 
Nursing Informatics Competency Based Assessment for Nursing Personnel in Primary Healthcare Centers in Tabuk

\section{RESULTS}

Table1. Percentage distribution of personal data for nursing personnel ( $N=217)$.

\begin{tabular}{|c|c|c|c|}
\hline & Personal data & No & $\%$ \\
\hline \multicolumn{4}{|c|}{$>$ Gender } \\
\hline • & Male & 71 & 32.7 \\
\hline$\bullet$ & Female & 146 & 67.3 \\
\hline \multicolumn{4}{|c|}{$>$ Age (years) } \\
\hline$\bullet$ & Mean \pm SD & \multicolumn{2}{|c|}{$33.54 \pm 4.82$} \\
\hline 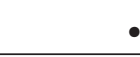 & Range & \multicolumn{2}{|c|}{$(25-47)$} \\
\hline \multicolumn{4}{|c|}{$>$ Years of experience } \\
\hline 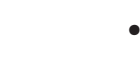 & Mean \pm SD & \multicolumn{2}{|c|}{$11.48 \pm 5.93$} \\
\hline 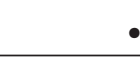 & Range & \multicolumn{2}{|c|}{$(2-27)$} \\
\hline \multicolumn{4}{|c|}{$>$ Level of Education } \\
\hline$\bullet$ & Diploma & 24 & 11.1 \\
\hline • & Associated nursing degree & 143 & 65.9 \\
\hline$\bullet$ & Bachelor & 50 & 23 \\
\hline \multicolumn{4}{|c|}{$>$ Area of Assignment } \\
\hline$\bullet$ & Chronic disease clinic & 57 & 26.3 \\
\hline$\bullet$ & Triage & 33 & 15.2 \\
\hline • & Dressing clinic & 25 & 11.5 \\
\hline$\bullet$ & Immunization & 24 & 11.1 \\
\hline$\bullet$ & Maternal clinic & 24 & 11.1 \\
\hline$\bullet$ & Others & 19 & 8.7 \\
\hline$\bullet$ & Health education & 13 & 5.9 \\
\hline$\bullet$ & Well baby clinic & 11 & 5.1 \\
\hline 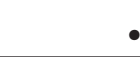 & Nurse administration & 11 & 5.1 \\
\hline
\end{tabular}

Table (1) describes the personal data for nursing personnel.The highest percentage of nursing personnel was female (67.3\%) while only (32.7\%) were male. Regarding their age ranged between (25-47) years and the mean was 33.54 \pm 4.82 . Regarding the level of education for nursing personnel, more than half of study sample (65.9\%) had associated nursing degree, and less than one third of them (23\%) had bachelor degree in nursing, while only (11.1\%) had Diploma in nursing. Pertaining their years of experience ranged (2-27) and the mean was $11.48 \pm 5.93$. In consideration to area of assignment, about one quarter of nursing personnel (26.3\%) were assigned in chronic disease clinic, $(15.2 \%)$ in triage and (11.5\% \& $11.1 \%)$ were working in dressing clinic and in immunization and maternal clinic respectively. Also (8.7\%) working in other area included school health, infection control, patient experience and general clinic. While only (5.9\% \& 5.1\%) work in health education and work in well baby clinic and nursing administration respectively. 
Nursing Informatics Competency Based Assessment for Nursing Personnel in Primary Healthcare Centers in Tabuk

Table2. Percentage distribution of Computer Literacy Competencies for the nursing personnel (N=217)

\begin{tabular}{|c|c|c|c|c|c|c|}
\hline \multirow{2}{*}{ Computer Literacy Competencies } & \multicolumn{2}{|c|}{ Not Capable } & \multicolumn{2}{|c|}{ Partial Capable } & \multicolumn{2}{|c|}{ Capable } \\
\hline & No & $\%$ & No & $\%$ & No & $\%$ \\
\hline $\begin{array}{l}\text { 1. I can define the basic components of } \\
\text { computer system such as: mouse, keyboard } \\
\text { CPU.., etc }\end{array}$ & 2 & 0.9 & 33 & 15.2 & 182 & 83.9 \\
\hline $\begin{array}{l}\text { 2. I can define the computer peripheral devises } \\
\text { (CD-ROM, USB and printers). }\end{array}$ & 11 & 5 & 42 & 19.4 & 164 & 75.6 \\
\hline $\begin{array}{l}\text { 3. I can use the external computer devises such } \\
\text { as flash drive printer and digital camera. }\end{array}$ & 30 & 13.8 & 53 & 24.4 & 134 & 61.8 \\
\hline $\begin{array}{l}\text { 4. I can use different connecting devise to } \\
\text { internet (phone line, mobile phone, cable } \\
\text { and wireless). }\end{array}$ & 12 & 5.5 & 51 & 23.5 & 154 & 71 \\
\hline $\begin{array}{l}\text { 5. I can determine the enough knowledge } \\
\text { about the copyright regarding computer } \\
\text { program and electronic files. }\end{array}$ & 56 & 25.8 & 63 & 29 & 98 & 45.2 \\
\hline $\begin{array}{l}\text { 6. I can create, rename, move and delete file } \\
\text { using computer operating system. }\end{array}$ & 30 & 13.8 & 51 & 23.5 & 136 & 62.7 \\
\hline $\begin{array}{l}\text { 7. I can use the word processing function such } \\
\text { as copy, paste, save and delete. }\end{array}$ & 30 & 13.8 & 43 & 19.8 & 144 & 66.4 \\
\hline $\begin{array}{l}\text { 8. I can demonstrate database program to build } \\
\text { simple database or make table. }\end{array}$ & 70 & 32.3 & 73 & 33.6 & 74 & 34.1 \\
\hline $\begin{array}{l}\text { 9. I can (create) make presentations using } \\
\text { presentation program (e.g PowerPoint). }\end{array}$ & 51 & 23.5 & 73 & 33.6 & 93 & 42.9 \\
\hline $\begin{array}{l}\text { 10. I can send, replay and forward the e-mail } \\
\text { massage and attachment. }\end{array}$ & 38 & 17.5 & 51 & 23.5 & 128 & 59 \\
\hline $\begin{array}{l}\text { 11. I can know where to find available resources } \\
\text { to resolve computer problems. }\end{array}$ & 73 & 33.6 & 72 & 33.2 & 72 & 33.2 \\
\hline $\begin{array}{l}\text { 12. I can determine the basic computer system } \\
\text { error (trouble shouting). }\end{array}$ & 72 & 33.2 & 67 & 30.9 & 78 & 35.9 \\
\hline $\begin{array}{l}\text { 13. I can save my time and efforts by using the } \\
\text { computer system. }\end{array}$ & 25 & 11.5 & 88 & 40.6 & 104 & 47.9 \\
\hline $\begin{array}{l}\text { 14. I can provide safe nursing care by using } \\
\text { computer technology. }\end{array}$ & 8 & 3.7 & 74 & 34.1 & 135 & 62.2 \\
\hline
\end{tabular}

Table (2) reveals Computer Literacy competencies for the nursing Personnel. About one third of the study subject $(32 \%, 33.6 \%$ \& $33.6 \%)$ were not capable in demonstrate database program to build simple database or make table, find available resources to resolve computer problems and determine the basic computer system error (trouble shouting) respectively. On the other hand (0.9\%) of them were not capable in define the basic components of computer system. In regard to partially capable competencies, (40\%) of the study subject stated that they were saving their time and efforts by using the computer system. While only (15.2\%) of them partially capable to define the basic components of computer system. Furthermore, majority of study sample (83\%) were capable to define the basic components of computer system such as: mouse, keyboard and only (33.2\%) capable to know where to find available resources to resolve computer problems. 
Nursing Informatics Competency Based Assessment for Nursing Personnel in Primary Healthcare Centers in Tabuk

Table3. Percentage distribution of Information Management Literacy competencies for the nursing personnel $(N=217)$

\begin{tabular}{|c|c|c|c|c|c|c|}
\hline \multirow{2}{*}{ Information Management Literacy Competencies } & \multicolumn{2}{|c|}{ Not Capable } & \multicolumn{2}{|c|}{ Partial Capable } & \multicolumn{2}{|c|}{ Capable } \\
\hline & No & $\%$ & No & $\%$ & No & $\%$ \\
\hline $\begin{array}{l}\text { I. I can seek lifelong continuous information regarding } \\
\text { nursing care. }\end{array}$ & 9 & 4.1 & 47 & 21.7 & 161 & 74.2 \\
\hline $\begin{array}{l}\text { 2. I can know when I should seek further information } \\
\text { during nursing practice. }\end{array}$ & 14 & 6.5 & 61 & 28.1 & 142 & 65.4 \\
\hline $\begin{array}{l}\text { 3. I can identify the primary and secondary source of } \\
\text { information. }\end{array}$ & 38 & 17.5 & 88 & 40.6 & 91 & 41.9 \\
\hline $\begin{array}{l}\text { 4. I can make good clinical question based on the } \\
\text { clinical situation. }\end{array}$ & 36 & 16.6 & 77 & 35.5 & 104 & 47.9 \\
\hline $\begin{array}{l}\text { 5. I can determine have enough knowledge about } \\
\text { the scientific information recourses to answer the } \\
\text { clinical questions. }\end{array}$ & 31 & 14.3 & 82 & 37.8 & 104 & 47.9 \\
\hline $\begin{array}{l}\text { 6. I can define the most appropriate methods to } \\
\text { accessing information electronically. }\end{array}$ & 36 & 16.6 & 93 & 42.9 & 88 & 40.6 \\
\hline 7. I can conduct the on-line literature search. & 12 & 5.5 & 67 & 30.9 & 138 & 63.6 \\
\hline $\begin{array}{l}\text { 8. I can determine the cultural, physical and other } \\
\text { context within which the information was created } \\
\text { an the effect on the information nature. }\end{array}$ & 20 & 9.2 & 81 & 37.3 & 116 & 53.5 \\
\hline $\begin{array}{l}\text { 9. I can synthesis the conclusion of information } \\
\text { obtained that can use effectively. }\end{array}$ & 11 & 5.1 & 94 & 43.3 & 112 & 51.6 \\
\hline $\begin{array}{l}\text { 10. I can identify the gaps in the information retrieved } \\
\text { and decide the need to repeat the search. }\end{array}$ & 43 & 19.8 & 87 & 40.1 & 87 & 40.1 \\
\hline $\begin{array}{l}\text { 11. I can review and validate, the accuracy, reliability of } \\
\text { information obtained. }\end{array}$ & 27 & 12.4 & 96 & 44.2 & 94 & 43.3 \\
\hline $\begin{array}{l}\text { 12. I respect and protect the patient data confidentially } \\
\text { and the information copyright. }\end{array}$ & 1 & 0.5 & 35 & 16.1 & 181 & 83.4 \\
\hline $\begin{array}{l}\text { 13. I can combine my clinical experiences to the new } \\
\text { information. }\end{array}$ & 5 & 2.3 & 51 & 23.5 & 161 & 74.2 \\
\hline $\begin{array}{l}\text { 14. I can participate the knowledge with the other } \\
\text { colleagues and the patients. }\end{array}$ & 0 & 0 & 31 & 14.3 & 186 & 85.7 \\
\hline $\begin{array}{l}\text { 15. I can comply with legal and regulatory requirements, } \\
\text { ethical standard and organization policies and } \\
\text { procedures regarding information management. }\end{array}$ & 4 & 1.8 & 48 & 22.1 & 165 & 76.1 \\
\hline
\end{tabular}

Table (3) clarifies Information Management Literacy competencies for the study subjects. (19.8\%) of nursing personnel were not capable in identify the gaps in the information retrieved and decide the need to repeat the search and no one on study subjects were not capable to participate the knowledge with the other colleagues and the patients. In regard to partial capable competencies $(44.2 \%)$ of them partial capable to review and validate, the accuracy, reliability of information obtained. Meanwhile, only (14.3\%) of them were partially capable to participate the knowledge with the other colleagues and the patients. However, the majority of study subjects (85\%) were capable to participate knowledge with the other colleagues and the patients and only (40.1\%) can identify the gaps in the information retrieved and decide the need to repeat the search. 
Nursing Informatics Competency Based Assessment for Nursing Personnel in Primary Healthcare Centers in Tabuk

Table4. Percentage distribution of Informatics Literacy Competencies for the nursing personnel (N=217)

\begin{tabular}{|c|c|c|c|c|c|c|}
\hline \multirow{2}{*}{ Informatics Literacy competencies } & \multicolumn{2}{|c|}{ Not Capable } & \multicolumn{2}{|c|}{ Partial Capable } & \multicolumn{2}{|c|}{ Capable } \\
\hline & No & $\%$ & No & $\%$ & No & $\%$ \\
\hline I use the trended healthcare information technologies & 3 & 1.4 & 62 & 28.6 & 152 & 70.0 \\
\hline $\begin{array}{l}\text { 2. I can advocate and encourage incorporating } \\
\text { innovations and information technologies into } \\
\text { nursing practice. }\end{array}$ & 13 & 6.0 & 77 & 35.5 & 127 & 58.5 \\
\hline $\begin{array}{l}\text { 3. I can participate in design, selection, } \\
\text { implementation and evaluation of health care } \\
\text { information technologies }\end{array}$ & 30 & 13.8 & 89 & 41.0 & 98 & 45.2 \\
\hline $\begin{array}{l}\text { 4. I can capture and used data related to clinical issues } \\
\text { by using information technologies such as EHR. }\end{array}$ & 32 & 14.7 & 72 & 33.2 & 113 & 52.1 \\
\hline $\begin{array}{l}\text { 5. I can use policies and procedures to use EHR in such } \\
\text { as patient admission, discharge and referral }\end{array}$ & 9 & 4.1 & 92 & 42.4 & 116 & 53.5 \\
\hline $\begin{array}{l}\text { 6. I can track of referral between care providers or } \\
\text { health care organizations }\end{array}$ & 34 & 15.7 & 57 & 26.3 & 126 & 58.1 \\
\hline $\begin{array}{l}\text { 7. I can document the patient data into Electronic } \\
\text { Health Records }\end{array}$ & 21 & 9.7 & 58 & 26.7 & 138 & 63.6 \\
\hline $\begin{array}{l}\text { 8. I can extract the data from clinical data set such as } \\
\text { EHR to initiate quality improvement project. }\end{array}$ & 23 & 10.6 & 84 & 38.7 & 110 & 50.7 \\
\hline $\begin{array}{l}\text { 9. I can generate and record the patient specific } \\
\text { information from EHR related to patient care. }\end{array}$ & 27 & 12.4 & 55 & 25.3 & 135 & 62.2 \\
\hline $\begin{array}{l}\text { 10. I can protect the patient data confidentially by log out } \\
\text { of system and user password protection. }\end{array}$ & 14 & 6.5 & 57 & 26.3 & 146 & 67.3 \\
\hline $\begin{array}{l}\text { 11. I can capture, review medical and surgical } \\
\text { procedures. }\end{array}$ & 27 & 12.4 & 66 & 30.4 & 124 & 57.1 \\
\hline $\begin{array}{l}\text { 12. I can determine the sufficient Knowledge about } \\
\text { medication administration using Information } \\
\text { technologies such as barcode scanning medication } \\
\text { administration. }\end{array}$ & 46 & 21.2 & 69 & 31.8 & 102 & 47.0 \\
\hline $\begin{array}{l}\text { 13. I can prepare personalized health education based } \\
\text { on patient health data }\end{array}$ & 16 & 7.4 & 53 & 24.4 & 148 & 68.2 \\
\hline $\begin{array}{l}\text { 14. I can provide safe nursing care by using the } \\
\text { information technologies }\end{array}$ & 10 & 4.6 & 67 & 30.9 & 140 & 64.5 \\
\hline $\begin{array}{l}\text { 15. I can identify the most common Electronic health } \\
\text { Records EHR system error (trouble shouting) }\end{array}$ & 38 & 17.5 & 114 & 52.5 & 65 & 30.0 \\
\hline 16. I can perform basic trouble shouting of EHR. & 45 & 20.7 & 90 & 41.5 & 82 & 37.8 \\
\hline $\begin{array}{l}\text { 17. I can respond to system errors alerts error such as } \\
\text { incomplete data entered. }\end{array}$ & 45 & 20.7 & 72 & 33.2 & 100 & 46.1 \\
\hline $\begin{array}{l}\text { 18. I can report any uncontrolled system error to the } \\
\text { responsible. }\end{array}$ & 22 & 10.1 & 63 & 29.0 & 132 & 60.8 \\
\hline $\begin{array}{l}\text { 19. I can Complies with healthcare centers policies } \\
\text { regarding EHR and other clinical information } \\
\text { technologies. }\end{array}$ & 8 & 3.7 & 81 & 37.3 & 128 & 59.0 \\
\hline $\begin{array}{l}\text { 20. I can train the patients in using healthcare } \\
\text { information technologies. }\end{array}$ & 24 & 11.1 & 92 & 42.4 & 101 & 46.5 \\
\hline
\end{tabular}


Nursing Informatics Competency Based Assessment for Nursing Personnel in Primary Healthcare Centers in Tabuk

Table (4) illustrates Nursing Informatics Literacy competencies for the study subjects. Less than one quarter of them (20.7\%) were not capable to perform basic trouble shouting of EHR and can respond to system errors alerts error such as incomplete data entered. Meanwhile, only (1.4\%) of them were not capable to use the trended healthcare information technologies. Also, about half of the study subjects (52.5\%) were partially capable to identify the most common Electronic health Records EHR system error and only (24\%) can prepare personalized health education based on patient health data. Furthermore, the majority of the nursing personnel (70\%) were capable to use the trended healthcare information technologies while only (30\%) of them can identify the most common Electronic health Records EHR system error.

Table5. Percentage distribution of the total capability of different competencies of the study subjects ( $N=217)$.

\begin{tabular}{|c|c|c|}
\hline Total capability of different competencies & No & \% \\
\hline$\bullet \quad$ Capable & 113 & 52.1 \\
\hline$\bullet \quad$ Partial capable & 71 & 32.7 \\
\hline$\bullet \quad$ Not capable & 33 & 15.2 \\
\hline
\end{tabular}

Table (5) presents the total capability of different competencies of the study subjects. Slightly more than half of them (52.1\%) were capable regarding total nursing informatics competencies. Furthermore (32.7\%) were partially capable and only (15.2\%) were not capable.

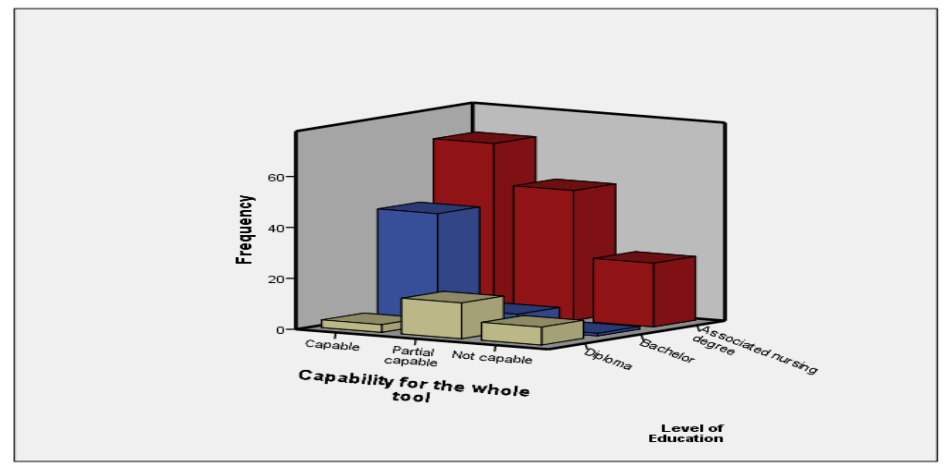

Fig1. Relationship between level of education in Nursing of the study subjects and capability

Figure (1) Table (11) \& Figure (4) demonstrate the relationship between the age and overall capabilities of nursing informatics. There is high statistically significant relation between level of education and capability in nursing informatics $(\mathrm{P}<0.001)$.

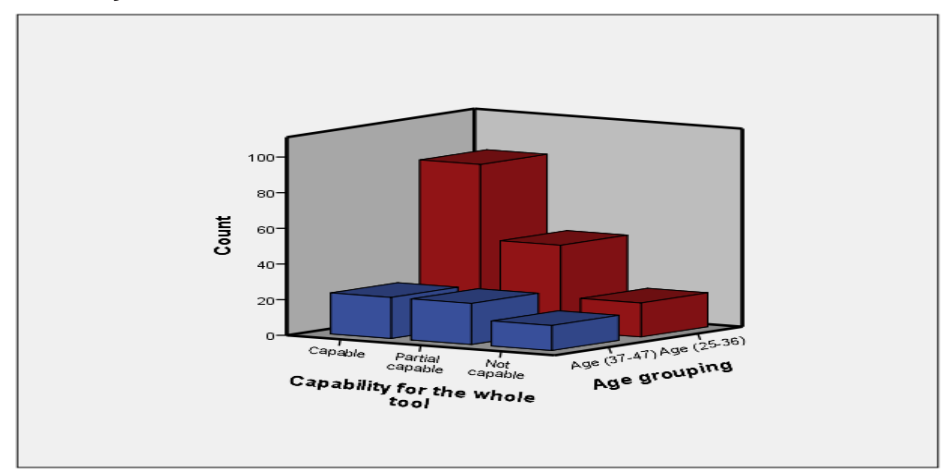

Fig2. Relationship between age of the study subjects and capability

Figure (2) shows the relationship between the age and overall capabilities of nursing informatics. There is a weak negative but highly significant correlation between age and total score in percentage, whereas the (P $<0.001$ ). 


\section{DISCUSSION}

Contemporary nursing profession require integration of many sciences, so it is crucial for nurses to be competent in such sciences to help advance of nursing practice and provide effective, safe and high- quality care (Liston and McKinnon 2017).The nursing workforce compromise the largest group of healthcare providers and make up the largest proportion of users for health information technologies. The lack of nursing informatics competencies leading nurses to use workarounds which result in reducing the desired benefits from these technologies which contribute in the health of population and overall outcomes of healthcare systems and safety concern (Rathert et. al., 2019).

Personal factors, such as age, gender and education has been recognized as factor affecting the development of the competence for nurses (Rizany, Hariyati et al. 2018). In the current study, the result indicates that the highest percentage of nursing personnel were female compered to male. This finding is in agreement with ministry of health statistics regarding the distribution of nursing workforce, the majority of nursing workforce in Tabuk was female shaped $73.89 \%$ of nurses and only $26.11 \%$ were male nurses (MOH, 2018). The results as explained by (Alboliteeh, Magarey et al. 2017) may stem from socio-cultural issues , gender specific facilities , segregation of the genders and religious.

This is supported by (Al-Dossary 2018) who stated that the unique structure of socio-cultural in Saudi Arabia may alter the gender balance among nursing workforce. It is mandated to provide the nursing care to female patients only by female nurses and this also applied to male. Add to that (Almadani 2018) who emphasized that the Saudi nurses prefer working in primary healthcare centers due to gender separation in working environment and fixed working hours. From the researcher's point of view, this is attributed to the nature of the study setting, where the need for the female nurses is greater than male, due to there are two separate sections for men and women, and clinics in the women's section more than the other.

Well-educated nurse is an essential factor to meet the required national and international standers to provide high-quality and safe nursing care. Regarding level of education in nursing of the study subjects, the results indicate that more than half of study sample had associated nursing degree and less than one third of them had bachelor degree in nursing, while only less percentage were nurses with Diploma in nursing. This is consistent with (Almadani 2018) who found that bachelor's degree is the minimum entry into practice in Saudi Arabia, but most of the nursing workforces in Saudi Arabia are Diploma holders. It is usually applied the term Diploma to both nurses who graduates from technical institutes (associated nursing degree) and intermediate university colleges.

Results of the current study regarding level of education and overall capabilities of nursing informatics revealed that the majority of study subject with bachelor degree capable while approximately half of nurses with associate nursing degree capable. This is in agreement with (Mugomeri, Chatanga et al. 2016, Kleib and Nagle 2018, Hassona and Ali 2019) who reported that level of education was significantly impact on nursing informatics competencies. Furthermore, this is consistence with competency of using the electronic health record system was correlated with education level in which majority of nurses with postsecondary education was less capable and nurses with master degree with had higher competency. Also this supported by study of (Gilmour, Strong et al. 2016) who examined the nurses utilization and retrieval of online health information and found that the level of nursing education was associated with computer confidence and information retrieval.

On the other hand, (Elsayed, Hussein et al. 2017, Liston and McKinnon 2017) found that education level was not statistically correlated with nursing informatics competencies. This may due to that most of participants was bachelor degree and few of them master degree. These findings from the researcher's point of view may indicate that including computer and informatics curriculum in current nursing education program affected directly to enhance the nursing informatics competencies. 
Age was not a considered as a factor in developing policies and guidelines to streamline the continuing nursing education in nursing informatics. In addition age was not an excuse for nurses' lack of competence in nursing informatics as it was imperative to improve patient safety and quality of care. Although, this did not mean that there was less sensitivity to the differentiated needs and capacities of the respondents in the older generation. Regarding age in the present study, the mean age of study subject was filling in the young adult age group. Which means they are within active age of profession services and they have long years for nursing services. This means more professional service in nursing and makes it impactive for healthcare organizations. Which will in turn may ensure that they have the informatics competencies required to help advance nursing profession, and providing safe nursing care (Olajubu, Irinoye et al. 2014). In contrast (Ryan, Bergin et al. 2017) reported that in other countries such as United States, Canada and Australia confronted the challenges of aging nurses, where it is noted that registered nurses aged 50 or older ranged between $37 \%$ to $50 \%$ of nursing workforce.

However, the current study found that there is relationship between nursing informatics competencies and nurses 'age. This is in agreement with (Olajubu, Irinoye et al. 2014, Liston and McKinnon 2017, Hassona and Ali 2019) who found that nurses' age inverse correlated with nursing informatics competencies. This is expected result as younger nurses receive and exposed to technology versus to older nurses. Moreover, this was supported by study of (Mullings and Ngwenyama 2018) who elaborated that the acceptance factors of electronic health records among young nurses is high while, in aging nurses or older nurses reported that they did not have sufficient experience with computer which may led to ineffective use and un acceptance of newly adopted systems.

Furthermore, This was supported by (Ryan, Bergin et al. 2017) who found that although the patients prefer to receive care from the older nurses, the older nurses perceived as less capable because they have not the equal chances to progress as for young nurses. In contrast (Alshammari 2017) reported that nurses' age was not associated with nursing informatics competencies.

The experience and the nursing informatics competencies was inverse significant associated in the present study. The same was found by (Olajubu, Irinoye et al. 2014, Kwak, Kim et al. 2017) who interpreted the findings as young nurses graduated from program included the computer in their curricula, while, the older nurses were not have the same chance. So, they lack the experience and education in computer uses and other information technologies. The opposing findings were by (Alshammari , Liston and McKinnon 2017) who reported there is no correlation between the experience and competency of nursing informatics among study participants.

The computer competency is core competencies required in contemporary nursing practice with continuous technological involvement and advancement in healthcare sectors. With the adoption of electronic health records in healthcare institution, nurses required to have competencies in utilizing computer to provide safe and effective nursing care. In the current study, less than half of study subjects were capable of computer literacy competency.This result congruence with several studies which demonstrated that nurses participates remarked above the mark of competent in computer literacy competency (Alshammari, Liston and McKinnon 2017, Ramukumba and El Amouri 2017, Hassona and Ali 2019).

In addition this was supported by (Hassona and Ali 2019) who stated that the increases of computer competencies among nurses may be resulted from the majority of the study subjects have computer education previously. This was in agreement with (Kinnunen et.al 2019) who interpreted that the high level of competencies regarding computer skill and information may due to the changing in nursing curriculum and including the basic computer in nursing baccalaureate program from several years and continuous nursing education regarding nursing informatics in their hospital. However, (Kirkova-Bogdanova 2017) found that the healthcare students have good computer skills and assert to introduce the advanced skill in the informatics course which will lead them to upgrade their competencies.

American Research Journal of Nursing Page 11 
On the other hands , (Elsayed, Hussein et al. 2017) found that computer literacy subscale has the lowest mean score compared with informatics literacy or informatics management subscales. Similarly, study by (Mugomeri, Chatanga et al. 2016) who aimed to assess the computer literacies among nurses, found that $60 \%$ of nurses in study were inadequate regarding computer skills. In alignment of previous study, the study of (Liston and McKinnon 2017) revealed nurses rated themselves beginners in advanced computer competencies and explained that as a result of training of nursing informatics has been below the expectation in nursing programs and post graduate education.

Moreover, this supported by (Habibi-Koolaee, Safdari et al. 2015) who found that that computer skills of nurses need to be enhanced and it is necessary to conduct training program about computer skills to improve dealing with technological working environment. Also, (Isaac 2015) examined the healthcare professional's basic computer skills thorough actual test and self-assessment test.The findings showed that, the score of self-assessment significant higher than the score of actual test. This explained the reason behind high level of computer skills scores among studies in which the nurses may over assessed themselves regarding the competencies. From the researcher's view of point to that now a days the technology was involved in every aspect of the life which in turn led to the development of computer skills among participants, even if the computer curriculum did not included in some the nursing education programs.

The Information management competency according to TIGER is the nursing ability to recognize the need of information, locate, evaluate and applying this information appropriately. When nurses are competent in information management, timely, best and accurse access to information which will lead to enhance decision making (Al-Hawamdih and Ahmad 2018). The study results presented that more than half of the study subjects were capable regarding the total capability of information management literacy and less than ten percent of them were not capable. Whereas the most inadequate competencies as rated by them identify the gaps in the information retrieved and partial capable were decide the need to repeat the search review and validate, the accuracy, reliability of information obtained. Similarly to the findings of (Alshammari , Elsayed, Hussein et al. 2017) who found that the majority of study subjects were competent in information management. Also, this is agreed by (Farokhzadian, Khajouei et al. 2015) who found that nurses reporting inability to validate the quality of research paper as the biggest barrier to implement the evidence-based practice.

In contrast to (Hossana \& Ali 2019) who asserted that $70 \%$ of their study subjects were not competent and somewhat competent in information literacy.This is consistent with (CLN, CLN et al. 2018) who examined the information needed and information seeking behavior and revealed that lake of information literacy among practicing nurses. This was supported by (Intas, Kostagiolas et al. 2017, Zhong, Hu et al. 2018) who emphasized that it is imperative to integrate the information literacy education into nursing education programs in order to increase the competencies regarding information utilization, retrieval, and assessment. Also this agreed by (Sarbaz, Kimiafar et al. 2016, Aghazadeh-Asl, Ghassemi et al. 2017) who stated that increasing information literacy will lead to better decision making and nursing practice by effective use and access to information.

It is interesting that (Mills, Francis et al. 2015) asserted that developing knowledge and skills regarding information literacies will enhance the nurses productivity and support the adherence to healthcare standard and overall outcome. This was supported by (Grace and Jeyshankar 2014) who found that nurses utilizes informal media and resources to answer their clinical questions. However recommend the curriculum changes and increase the awareness regarding the scientific recourses. In addition to study conducted by (Kumaran and Chipanshi 2015) who examined the information literacies among nurses and found that there were lack of skills and knowledge regarding the utilization of scientific resources for clinical information so they depend on the internet (google) as resource for their information.

American Research Journal of Nursing Page 12 
The informatics literacies is applying the data to support clinical decisions, documentation, ensuring data integrity, confidentiality, and security to articulate the value of information system such as EHRs. The results of current study indicate that approximately half of them were capable and about one third of them were partial capable. These findings supported by (Alshammari , Elsayed, Hussein et al. 2017) who found that the nurses competency regarding the informatics literacies was the highest one. On the other hand, (Hossana \& Ali 2019) found that approximately $74 \%$ of nurses' less than competent regarding the informatics competencies. Add to that the result of (Olajubu, Irinoye et al. 2014) who indicated that the majority of the study subjects rated informatics competency to be below average. This result was in agreement with (Liston and McKinnon 2017) who found that nurses less than competent regarding the advanced informatics competencies.

Nursing informatics competencies is combination of computer literacy, informatics literacy, and information management competencies. The present study revealed that more than half of them were capable regarding total nursing informatics competencies, approximately one third of them were partially capable and few of them were not capable. Several studies in congruence with the findings, as they revealed majority of participants were competent in nursing informatics (Alshammari, Elsayed, Hussein et al. 2017, Hassona and Ali 2019). This result interpreted by (Elsayed, Hussein et al. 2017) who stated that the successful application of health information systems in most hospitals will reflect on the level of nurses' informatics competency. Moreover, this was supported by the findings of (Banihani, Al Qadire et al. 2019) who assessed the nursing attitude toward computerization, they stated that nurses who received training in electronic health records were more competent in using the electronic health Records. This is what emphasized by (Kleib and Nagle 2018) who assess the level of nursing informatics competencies and identify the factors associated with competency, one of the factor affecting the competency is continuous informatics education. This is supported by (Ahmed 2015) who reported that the higher level of nursing informatics competencies among the nursing intern compared to student due to the chance to use the health information systems and applications.

In contrast (Olajubu, Irinoye et al. 2014, Liston and McKinnon 2017) found that the majority of nursing participants rated themselves below than competent regarding total nursing informatics competencies. Furthermore, according to (AL-shamari 2017) who explained that this opposing findings can be explained by the participates who stated that lack of time and burden of responsibilities and given the priority to direct patient care imped their abilities to improve their informatics competencies. The burden of responsibility according to (Singh and Muthuswamy 2013) may result from duplication of efforts by using both written and electronic documentation of patient data especially during the first stage of adopting the electronic health records. Furthermore, the implementation plan of new adopting health information systems used could influences on their attitude and effects on the overall competencies regarding informatics. The is supported by (Hariyati, Hamid et al. 2020) who found that the initial phase of implementation of the health information program usually accompanied with feelings of frustration and anger due to the double documentation written and electronic. However, regarding the attitude toward electronic health records the doubt regarding its benefits for nursing practice among nurses. Having those doubt may resulted from failure to introduce the electronic health record effectively and insufficient continuous education and support from the information technology department by informatics nurses (Jahanbakhsh, Karimi et al. 2017).

\section{CONCLUSION}

This study assessed nursing informatics competencies for nursing personnel in primary healthcare centers in Tabuk and found that less than half of study subjects were capable of computer literacy competency. Meanwhile, one quarter of them were not capable and only few of them were partially capable. Regarding Information Management Literacy Competency, More than half of them were capable and about third of them were partially capable and only less than ten percent were not capable. Furthermore, approximately half of them were capable 
Nursing Informatics Competency Based Assessment for Nursing Personnel in Primary Healthcare Centers in Tabuk

of Informatics Literacy Competency. However, about third of nursing personnel were partially capable and less than ten percent were not capable. In addition more than half of them were capable regarding total nursing informatics competencies. Meanwhile, more than one third were partially capable and less than one quarter of them was not capable.

\section{RECOMMENDATIONS}

1. Based on the study findings, the following recommendations were suggested:

2. Apply recruitment and selection of the right number and types of employees to fulfill its strategic and operational goals.

3. Redesign the hospital policies and regulations to be adapted with new vision of King Saudi Arabia.

4. Involve nursing informatics competencies in nursing personnel performance appraisal.

5. Conducts competency based nursing informatics training programs for nursing personnel according to their needs and to be up to date with new competencies.

6. Develop curricular based competencies.

7. Further Research to investigate correlation between nursing informatics competencies and patient safety

\section{REFERENCES}

1. Aghazadeh-Asl, E., Ghassemi, A. H., Bigdeli, Z., Soosani-Gharibvand, B., \& Saki-Malehi, A. (2017). 116: Surveying the information seeking behavior and information need of nurses working in Ahvaz Hospitals affiliated to Jundishapur University of Medical Science in using up-to date Database. BMJ Open, 7(Suppl 1), bmjopen-2016-015415.116. https://doi.org/10.1136/bmjopen-2016-015415.116

2. Ahmed, A. (2015). Nursing Informatics Competencies Among Nursing Students and Their Relationship to Patient Safety Competencies Knowledge, Attitude, and Skills. 33: 509-514.

3. Al-Hawamdih, S. and M. M. Ahmad (2018). "Examining the relationship between nursing informatics competency and the quality of information processing." CIN: Computers, Informatics, Nursing 36(3): 154-159.

4. Al-Dossary, R. (2018). "The Saudi Arabian 2030 vision and the nursing profession: the way forward." International nursing review 65(4): 484-490.

5. Alboliteeh, M., J. Magarey and R. Wiechula (2017). "The profile of Saudi nursing workforce: A cross-sectional study." Nursing research and practice 2017.

6. Alshammari, F., Pasay-an, E. and Indonto, C. (2017).Competencies in Nursing Informatics in the Saudi Arabian Context: A Sequential Explanatory Study. Philippine Journal of Nursing. 87(2):45-55.

7. ANA (2015). "American Nurses Association. Nursing Informatics: Scope and Standards of Practice. (2nd, Ed.) Silver Spring, MD: Nursingbooks.org."

8. Banihani, S., M. Al Qadire and D. allah E’leimat (2019). "Attitudes of Jordanian Oncology Nurses Toward Computerization." Journal of Cancer Education: 1-5.

9. Bassi, J. (2016). "Vision 2030 and the Opportunities it Represents in Healthcare in Saudi Arabia." Retrieved February 25: 2019. 
Nursing Informatics Competency Based Assessment for Nursing Personnel in Primary Healthcare Centers in Tabuk

10. Chung, S. Y. and N. Staggers (2014). "Measuring nursing informatics competencies of practicing nurses in Korea: nursing informatics competencies questionnaire." CIN: Computers, Informatics, Nursing 32(12): 596-605.

11. CLN, B. O. M., U. E. CLN and N. G. Nwankwo (2018). "Information Need and Seeking Behaviour of Practising Nurses in Nigeria; the Case of Our Lady of Lourdes Hospital Ihiala." Library Philosophy and Practice: 1.

12. Elsayed, W. A., F. M. Hussein and W. N. Othman (2017). "Relation between nursing informatics competency and nurses' attitude toward evidence-based practice among qualified nurses at Mansoura Oncology Center." International Journal of Nursing Didactics 7(6): 26-33.

13. Farokhzadian, J., R. Khajouei and L. Ahmadian (2015). "Evaluating factors associated with implementing evidence-based practice in nursing." Journal of evaluation in clinical practice 21(6): 1107-1113.

14. Forman, T. M., D. A. Armor and A. S. Miller (2020). "A Review of Clinical Informatics Competencies in Nursing to Inform Best Practices in Education and Nurse Faculty Development." Nursing education perspectives 41(1): E3-E7.

15. Gilmour, J., A. Strong, H. Chan, S. Hanna and A. Huntington (2016). "Primary health-care nurses and Internet health information-seeking: Access, barriers and quality checks." International journal of nursing practice 22(1): 53-60.

16. Grace, M. and R. Jeyshankar (2014). "Information Seeking Behaviour of the Nursing Professionals of Apollo College of Nursing, Chennai.” International Journal of Information Research 3(3): 284-294.

17. Greer, H. (2012). "Nursing informatics Competencies: Implications for safe and Effective practice." Honors Theses.

18. Habibi-Koolaee, M., R. Safdari and H. Bouraghi (2015). "Nurses readiness and electronic health records." Acta Informatica Medica 23(2): 105.

19. Hariyati, R. T. S., A. Y. Hamid, T. Eryando and Z. A. Hasibuan (2020). "Usability and satisfaction of using electronic nursing documentation, lesson-learned from new system implementation at a hospital in Indonesia." International Journal of Healthcare Management 13(1): 45-52.

20. Hassona, F. M. and A. Z. Ali (2019). "Relationship between Nursing Informatics Competency and Innovativeness among Qualified Nurses." Evidence-Based Nursing Research 1(3): 9-9.

21. Houston, S. M., T. Dieckhaus, B. Kircher and M. Lardner (2018). An Introduction to Nursing Informatics, Evolution, and Innovation: Evolution and Innovation, CRC Press.

22. Hunter, K. M., D. M. McGonigle and T. L. Hebda (2013). "TIGER-based measurement of nursing informatics competencies: The development and implementation of an online tool for self-assessment." Journal of Nursing Education and Practice 3(12): 70.

23. Intas, G., P. Kostagiolas, D. Zavras, E. Chalari, P. Stergiannis, G. Toylia and D. Niakas (2017). "InformationSeeking Behavior of Greek Nursing Students: A Questionnaire Study." Computers, informatics, nursing : CIN 35(2): 109-114.

24. Isaac, J. P. (2015). Comparing basic computer literacy self-assessment test and actual skills test in hospital employees. Unpublished doctoral dissertation, Walden University, Washington 
Nursing Informatics Competency Based Assessment for Nursing Personnel in Primary Healthcare Centers in Tabuk

25. Jahanbakhsh, M., S. Karimi, A. Hassanzadeh and M. Beigi (2017). "Hospital managers' attitude and commitment toward electronic medical records system in Isfahan hospitals 2014." Journal of education and health promotion 6(36): 1-5.

26. Jing, W., X. Zhang, R. Chi, X. Sun and S. Lv (2019). "Exploration of Factors Influencing Nurse Competence Through Nursing Profile Analysis.” The Journal of Continuing Education in Nursing. 50(12): 572-580.

27. Karami, A., J. Farokhzadian and G. Foroughameri (2017). "Nurses' professional competency and organizational commitment: is it important for human resource management?" PLoS One. 12(11): 1-15

28. Kirkova-Bogdanova, A. (2017). Computer literacy of healthcare students from medical university-Plovdiv. CBU International Conference Proceedings.5.650-655.

29. Kleib, M. and L. Nagle (2018). "Factors associated with Canadian nurses' informatics competency." CIN: Computers, Informatics, Nursing 36(8): 406-415.

30. KumaranM., \& ChipanshiM. (2015). Exploring the Information-Seeking Behaviour of Internationally Educated Nurses (IENs) in Saskatchewan. Journal of the Canadian Health Libraries Association / Journal De l'Association Des bibliothèques De La Santé Du Canada, 36(2), 45-53. https://doi.org/10.5596/c15-013

31. Kwak, S. Y., Y. S. Kim, K. J. Lee and M. Kim (2017). "Influence of nursing informatics competencies and problem-solving ability on nursing performance ability among clinical nurses." J Korean Acad Soc Nurs Educ 23(2): 146.

32. Liston, J. and T. McKinnon (2017). "Self-Assessment of Perceived Informatics Competencies among Staff Nurses at Sutter Maternity and Surgery Hospital." Journal of Informatics Nursing 2(1): 12-16.

33. McGonigle, D., K. Hunter, C. Sipes and T. Hebda (2014). "Why nurses need to understand nursing informatics." AORN journal 100(3): 324-327.

34. Mills, J., K. Francis, M. McLeod and M. Al-Motlaq (2015). "Enhancing computer literacy and information retrieval skills: A rural and remote nursing and midwifery workforce study." Collegian 22(3): 283-289.

35. Mugomeri, E., P. Chatanga, C. Maibvise and M. Masitha (2016). "Assessment of computer literacy of nurses in Lesotho." CIN: Computers, Informatics, Nursing 34(11): 528-534.

36. Olajubu, A. O., Irinoye, O. O., \& Olowokere, A. E. (2014). Competencies and Barriers to the Use of Nursing Informatics among Nurses in Primary, Secondary and Tertiary Healthcare Facilities in Nigeria. Journal of Health Informatics in Africa, 2(1). https://doi.org/10.12856/JHIA-2014-v2-i1-85

37. Ramukumba, M. M. and S. El Amouri (2017). "Nurses' level of computer literacy, attitudes and responses regarding the electronic health record system in the United Arab Emirates." Africa Journal of Nursing and Midwifery 19(2):14

38. Rathert, C., T. H. Porter, J. N. Mittler and M. Fleig-Palmer (2019). “Seven years after Meaningful Use: Physicians' and nurses' experiences with electronic health records." Health care management review 44(1): 30-40

39. Rizany, I., R. T. S. Hariyati and H. Handayani (2018). "Factors that affect the development of nurses' competencies: a systematic review." Enfermeria clinica 28: 154-157.

40. Ryan, C., M. Bergin and J. Wells (2017). "Valuable yet vulnerable-a review of the challenges encountered by older nurses in the workplace." International journal of nursing studies 72: 42-52. 
Nursing Informatics Competency Based Assessment for Nursing Personnel in Primary Healthcare Centers in Tabuk

41. Sarbaz, M., K. Kimiafar, A. Sheikhtaheri, Z. Taherzadeh and S. Eslami (2016). Nurses' Information Seeking Behavior for Clinical Practice: A Case Study in a Developing Country. Nursing Informatics. 225: 23-27.

42. Singh, B. and P. Muthuswamy (2013). "Factors affecting the adoption of electronic health records by nurses." World Applied Sciences Journal 28(11): 1531-1535.

43. Zadvinskis, I. M., J. G. Smith and P.-Y. Yen (2018). “Nurses' experience with health information technology: Longitudinal qualitative study." JMIR medical informatics 6(2): e38.

44. Strudwick, G., L. McGillis Hall, L. Nagle and P. Trbovich (2018). "Acute care nurses' perceptions of electronic health record use: a mixed method study." Nursing Open 5(4): 491-500.

45. Zhong, Z., D. Hu, F. Zheng, S. Ding and A. Luo (2018). "Relationship between information-seeking behavior and innovative behavior in Chinese nursing students." Nurse education today 63: 1-5.

Citation: Zakiah Eid Al-Balawi, Eman Salman Taie, Naglaa Alsesei, "Nursing Informatics Competency Based Assessment for Nursing Personnel in Primary Healthcare Centers in Tabuk". American Research Journal of Nursing. 2020; 6(1): 1-17.

Copyright (c) 2020 Zakiah Eid Al-Balawi, Eman Salman Taie, Naglaa Alsesei, This is an open access article distributed under the Creative Commons Attribution License, which permits unrestricted use, distribution, and reproduction in any medium, provided the original work is properly cited. 